\title{
Stop Sacrificing Children to Moloch
}

\author{
Erik Gilbert \\ Arkansas State University \\ egilbert@astate.edu
}

\begin{abstract}
Erik Gilbert extends his extensive expertise on the assessment and evidence cultures in higher education here with a creative metaphor, a fable. He invites us to consider the Biblical God Moloch, and how through assessment obsession we're participating in an archaic and illogical practice as inhumane as sacrificing children.
\end{abstract}

Keywords: Fable, assessment, bad assessment, metis, evidence

As someone who has been publicly critical of learning outcomes assessment for a long time, one of the most common questions I am asked is: "If you are so opposed to assessment, what would you replace it with?" By way of an answer I have started resorting to this fable:

Imagine that you live in a Bronze Age village. You and everyone else in the village depend for your livelihood on subsistence farming, so you have a keen interest in the success of your crops. Because of that, you have developed a good sense of when to plant what crop, what types of soil work best with specific crops, when to weed, when to harvest and so on. It's not scientific knowledge but it works pretty well. Still, you are always on the lookout for ways of improving your yields.

One day a group of priests shows up. They hold an information session at which they advise you that in the imperial capital (which, of course, taxes your crops), the authorities are concerned that the crop yields in the villages (and thus the tax revenues) are not what they could be. They would like to see that change.

The priests point out that most of the other villages have begun sacrificing children to Moloch in order to improve their yields. Reluctantly, your village agrees to start sacrificing children to Moloch in the hope that He will reward you with better harvests.

At first, it seems to be working. Soon the village has a new temple to Moloch and a clutch of recently hired associate and assistant priests. But after a couple of harvests your yields have reverted to the mean.

A delegation of farmers goes to the priests and asks what the problem is.

Moloch, you are told, does not bestow His favors on those who just go through the motions of sacrificing children. You need to buy-in to the process, to commit, to really have faith, or it won't work. 
So you stop making the most junior farmers do all the sacrificing, you start spending more time going to tedious ceremonies devoted to Moloch, and really try to commit.

Still, the crop yields don't change. You go back to talk to the priests. You note that that there is now a new wing on the building and the temple complex is starting take up good arable land that you once used to produce food.

You tell them that your crop yields seem about the same, but the relentless expansion of the temple complex is cutting into the total production of food.

They respond that Moloch worship was never really about crop yields. It's more about the conversations it sparks about how much we care about our crops and how it lets us reflect on what we and Moloch value about our children. And don't forget, the imperial tax collector, and the Solaria Foundation that advises him, feel very strongly about the importance of Moloch worship. And anyway, what would you replace Moloch worship with if we did stop? Don't you care about the crops? to Mithras?

So how would we replace Moloch worship? Golden Calves to Ba'al? Cats to Isis? Bulls

Or, might it be a positive step just to stop sacrificing children to Moloch? There would be fewer resources squandered on the temple and the priests. The land the temple sits on could be put back in cultivation and even if your yields remained the same, at least you would have a little more land in production. And the time and resources saved could be applied to the sort of seat-ofthe-pants improvements that the farmers were making already.

This is pretty much where we are now with assessment. Assessment is just as effective as and no more grounded in evidence than the cult of Moloch. No one can show that 30 years of assessment has caused improvements in student learning. The arguments for assessment are more faith-based than scientific. That it has not yielded results is attributed to the faculty's lack of faith (aka "buy-in"). Conveniently this is an unfalsifiable argument in that faith is hard to measure, so assessors can always fall back on the "not enough buy-in" argument any time someone points out that assessment can't be shown to improve student learning. And just making that observation is seen as an example of people like me not buying in to assessment. But assessment, with its apparently dispassionate data, rubrics and matrices seems to meet some profound bureaucratic need.

James Scott's book Seeing Like a State offers a useful term for this. Scott uses the term metis, which is a Greek word for the practical, hands-on knowledge that people with direct experience of a problem have. Metis would be the gut-level sense that you have after the midterm exam that you need to back and explain what dramatic irony is. He contrasts that with enforced, top-down expertise that colonial officials, development experts, priests of Moloch, accreditors and Assessment Offices all claim to have. These representatives of the high modernist impulse seek to boil down complex problems that are embedded in a particular local context into the simple, linear, legibility (his term) of the official form, the matrix or in our case the rubric. 
Scott points to any number of disasters that have resulted from experts' efforts to impose legibility in situations where they would have been far better off deferring to the metis of the people they were trying to help. Soviet collective farming, German scientific forestry, and the colonial era Groundnut Scheme in Tanganyika are among his examples.

Rather than concede that the metis of the faculty is superior to, or at least no worse, and lot a cheaper than the demonstrable failures of assessment our accreditor overlords and their campus-based commissars continue to demand documented legible "evidence" of student learning. If Scott's case studies are any guide, this won't end well.

As with Moloch worship, just stopping assessment would bring benefits: fewer wasted resources, many fewer meetings, and less administrative intrusion into the curriculum.

We have nothing to lose and much to be taking couple of years off from assessment. If anyone can detect a change in student learning after that, we will consider our options. I am confident that there will be no need to dust off our rubrics and curriculum maps. 